\title{
Synthesis of Oxindoles and Benzofuranones via Oxidation of 2-Heterocyclic BMIDAs
}

\section{Ciaran P. Seath}

James W. B. Fyfe

John J. Molloy

Allan J. B. Watson*

Synthesis 2017, 49, 891.

A typing error in the title has been corrected for the final online and print versions. 